\title{
COVID-19 progression in kidney transplant recipients: a single-center case series
}

\author{
Hormat Rahimzadeh ${ }^{1,2,3}$ (1) Mohammad Keykhaei $^{4} \cdot$ Effat Razeghi $^{1,5} \cdot$ Ensieh Zivari $^{1} \cdot$ Ensieh Sadat Mansouri $^{1}$
}

Received: 17 October 2020 / Accepted: 12 February 2021 / Published online: 26 March 2021

(C) Japanese Society of Nephrology 2021

\begin{abstract}
The novel coronavirus disease 2019 (COVID-19) is a respiratory infection that has received much attention due to its rapid expansion. Currently, it has been revealed that patients with underlying disease, especially those with kidney disease are more prone to develop complications. Some studies associate kidney transplantation as a risk factor for COVID-19 progression; however, epidemiologic data that demonstrate this are amazingly rare. Considering the importance of the topic, we report on six kidney transplant recipients (median age 47 [41-55]) with confirmed or clinically suspected COVID-19. The most common admission presentations were fever (83.3\%), dyspnea, and myalgia. At baseline, immunosuppressive therapy was ceased, prednisolone dose was increased, and all patients received antiviral treatment including hydroxychloroquine and umifenovir. After a median follow-up of 11.5 days from admission, six patients (100\%) developed acute kidney injury (AKI), 50\% required intensive care unit (ICU) admission, and two patients (33.3\%) deceased as a result of deterioration in respiratory status. Overall, these findings demonstrate that respiratory involvement may be a risk indicator of in-hospital mortality in kidney recipients with COVID-19. In addition, AKI development in kidney recipients with COVID-19 is of utmost importance given the higher AKI occurrence in these patients compared with others. Therefore, more intensive attention should be paid to kidney transplant recipients with COVID-19.
\end{abstract}

Keywords AKI · COVID-19 - Immunosuppression · Kidney transplant

\section{Introduction}

Hormat Rahimzadeh

h-rahimzadeh@sina.tums.ac.ir

$\bowtie$ Ensieh Sadat Mansouri

encyesaadaat@yahoo.com

1 Department of Internal Medicine, Sina Hospital, Tehran University of Medical Sciences, Hasan Abad Sq, 11367-46911 Tehran, Iran

2 Research Development Center, Sina Hospital, Tehran University of Medical Sciences, Tehran, Iran

3 Urology Research Center, Sina Hospital, Tehran University of Medical Sciences, Tehran, Iran

4 Students' Scientific Research Center (SSRC), Tehran University of Medical Sciences, Tehran, Iran

5 Nephrology Research Center, Center of Excellence in Nephrology, Tehran University of Medical Sciences, Tehran, Iran
Since December 2019, severe acute respiratory syndromecoronavirus-2 (SARS-CoV-2) has become a global concern due to its rapid expansion. By October 17, 2020, the virus had caused 39,628,710 confirmed cases and 1,109,749 deaths worldwide [1]. The coronavirus disease 2019 (COVID-19) has various manifestations including acute respiratory distress syndrome (ARDS) and acute kidney injury (AKI). There are several mechanisms leading to kidney injury in patients with COVID-19, including cytokine storm syndrome, rhabdomyolysis, hypoxia, and dehydration due to fever or decreased intake of fluids. In addition, direct virus invasion to the renal tubular cells may contribute to kidney injury [2].

Given to the extent of the COVID-19 pandemic, it has been revealed that post-transplant immunosuppression makes kidney transplant recipients susceptible to viral pathogens. According to a study conducted by Pereira et al. [3], the history of transplantation may play a role in the development of COVID-19 complications; however, due to the low 
statistical population of previous studies, the management of COVID-19 in these patients still remains unknown. In this article, with regard to the importance of the topic, we retrospectively collected and analyzed clinical data of six kidney recipients with confirmed or clinically suspected COVID-19. The essential aim of our study is to investigate the association between kidney transplantation, as an underlying disease, and COVID-19 progression.

\section{Case series}

In this case series, we report clinical characteristics and outcomes of six kidney recipients with confirmed or clinically suspected COVID-19 in Sina Hospital, Tehran, from February 20 to May 14, 2020. The diagnosis was confirmed based on the following criteria: (1) positive polymerasechain-reaction (PCR) test of endotracheal or oropharyngeal swab specimens. (2) Highly suspicious patients according to the Iranian national committee of COVID-19 and the World Health Organization's interim guidance $[4,5]$. The Swab PCR test was performed for six (100\%) patients, of whom five $(83.3 \%)$ were definitely diagnosed with COVID-19 (patient 2 had a negative test). The median age of transplant recipients was 47 years (range 41-55 years) including four $(66.7 \%)$ women. Of six patients, three required intensive care unit (ICU) admission, and three were managed in the COVID-19 ward. Among three patients sent to ICU, two patients required intubation while the other one was managed only with non-invasive ventilation. At a median followup of 11.5 days (9-23), four patients discharged and two patients passed away (mortality rate of 33.3\%).

Clinical characteristics, outcomes, and laboratory findings of the patients, who all underwent kidney transplantation between 2007 and 2020 are shown in Tables 1 and 2 . Comorbidities included hypertension $(N=4)$ and autosomal dominant polycystic kidney disease $(N=1)$. The median time from symptom onset to admission was 10 days (7-30 days), and the most common symptoms were fever (five patients, $83.3 \%$ ) followed by dyspnea (four patients, $66.7 \%$ ) and myalgia (three patients, 50\%). Relevant laboratory tests of the six patients were measured at admission, which demonstrated that all patients had lymphopenia and elevated inflammatory biomarkers (Table 2). Computerized tomography (CT) of the chest was performed in all patients, which showed typical COVID-19 changes (moderate-to-severe multifocal ground-glass lesions). Comparing the baseline serum creatinine level (median 1.47, range 1.4-2.5) with the admission level revealed that all patients had developed AKI. Besides, five patients $(83.3 \%)$ had proteinuria on admission, ranging from trace to $3+$; however, with regard to the patients' clinical condition, quantitative analysis of 24-h urine collections was not feasible and no patient underwent kidney biopsy. Of note, triple immunosuppression with a cell cycle inhibitor (mycophenolate mofetil (MMF) in five patients and azathioprine in one patient), calcineurin inhibitors (CNIs), and glucocorticoids had been used in four patients (two were on sirolimus); however, during hospitalization, MMF and CNIs were ceased immediately except for cyclosporine, and prednisolone was increased (Table 1). During follow-up, all patients received IVIG and antiviral regimen, including hydroxychloroquine (HCQ) and umifenovir (arbidol), three patients took an additional regimen with lopinavir-ritonavir (kaletra). Besides, antibacterial therapy, including meropenem and piperacillin-tazobactam, was initiated considering the situation of patients.

Among the patients admitted to ICU, two patients deceased as a result of deterioration in respiratory status. Patients 4 and 6 were admitted with dyspnea and tachypnea. During hospitalization, their clinical conditions deteriorated, which were manifested by severe shortness of breath and a decrease in peripheral oxygen saturation despite the use of nasal oxygen delivery. Meanwhile, a repeated CT scan also showed diffuse bilateral infiltrations in favor of ARDS in patient 4 . They were intubated for mechanical ventilation and broad-spectrum antibiotics were administered; however, despite the efforts during hospitalization, they developed multi-organ failure and unfortunately, they deceased.

\section{Discussion}

In our case series, we discussed the clinical characteristics and the outcomes of the first six kidney recipients with COVID-19 in our Hospital. The mortality rate in our patients was in line with similar previous studies $[6,7]$. Kidney recipients with COVID-19 developed even higher AKI than critically ill patients in Wuhan, China [8]. Besides, we found that respiratory involvement may be the main cause of the disease progression in patients with COVID-19 who had received kidney transplantation.

The 2019 novel coronavirus enters human cells by binding its spike to the angiotensin-converting enzyme 2 (ACE2) receptor. Proximal tubular cells and podocytes express the ACE2 receptor, resulting in AKI by virus-induced cytopathic effect, which is manifested by hematuria, proteinuria, elevated levels of blood urea nitrogen (BUN), and serum creatinine [2]. In our case-series, AKI was defined according to kidney disease improving global outcomes (KDIGO) guideline [9]. In addition, the baseline $\mathrm{Cr}$ was determined as the last serum $\mathrm{Cr}$ within 8-365 days prior to admission. So far, several studies have addressed the casual pathway, linking AKI with COVID-19 progression [10, 11]. In support of this concept, Wang and colleagues [10] studied two patients with COVID-19 and chronic renal disease. They found AKI in both patients and concluded that COVID-19 
Table 1 Clinical features and outcomes of six kidney transplant patients with COVID-19

\begin{tabular}{|c|c|c|c|c|c|c|}
\hline & Patient 1 & Patient 2 & Patient 3 & Patient 4 & Patient 5 & Patient 6 \\
\hline \multicolumn{7}{|l|}{ Baseline characteristics } \\
\hline Age (year) & 41 & 55 & 44 & 52 & 49 & 45 \\
\hline Sex & Male & Male & Female & Female & Female & Female \\
\hline KT date & 2007 & 2017 & 2020 & 2004 & 2017 & 2019 \\
\hline Comorbidities & - & HTN-ADPKD & HTN & HTN & HTN & - \\
\hline \multicolumn{7}{|l|}{ Admission symptoms } \\
\hline Fever & + & + & + & + & - & + \\
\hline Dyspnea & - & - & + & + & + & + \\
\hline Myalgia & + & - & - & + & - & + \\
\hline \multicolumn{7}{|l|}{ Vital signs } \\
\hline Heart rate & 102 & 86 & 120 & 88 & 114 & 88 \\
\hline Respiratory rate & 24 & 18 & 30 & 28 & 26 & 28 \\
\hline SBP & 110 & 115 & 130 & 140 & 120 & 100 \\
\hline DBP & 70 & 70 & 80 & 80 & 70 & 60 \\
\hline Temperature $\left({ }^{\circ} \mathrm{C}\right)$ & 39.7 & 38.6 & 38 & 38.3 & 37 & 38.3 \\
\hline Oxygen saturation (\%) & 95 & 96 & 87 & 98 & 88 & 80 \\
\hline \multicolumn{7}{|l|}{ Baseline immunosuppression } \\
\hline MMF (mg) & 1500 & 1500 & 1500 & 1000 & - & 1500 \\
\hline Prednisolone (mg) & 5 & 5 & 5 & 5 & 20 & 5 \\
\hline Sirolimus (mg) & 1 & 1 & - & - & - & - \\
\hline Tacrolimus (mg) & - & - & 4.5 & - & 2 & 2 \\
\hline Cyclosporine (mg) & - & - & - & 75 & - & - \\
\hline Azathioprine (mg) & - & - & - & - & 50 (qod) & - \\
\hline \multicolumn{7}{|l|}{ Anti-viral treatment } \\
\hline HCQ & + & + & + & + & + & + \\
\hline Lopinavir-ritonavir & - & + & - & - & + & + \\
\hline Umifenovir & + & + & + & + & + & + \\
\hline \multicolumn{7}{|l|}{ In-hospital outcomes } \\
\hline $\begin{array}{l}\text { Renal or respiratory involve- } \\
\text { ment }\end{array}$ & AKI & AKI & AKI & AKI-ARDS & AKI & AKI \\
\hline Death & - & - & - & + & - & + \\
\hline
\end{tabular}

$A D P K D$ autosomal dominant polycystic kidney disease, $A K I$ acute kidney injury, $A R D S$ acute respiratory distress syndrome, COVID-19 coronavirus disease 2019, DBP diastolic blood pressure, HCQ hydroxychloroquine, $H T N$ hypertension, $K T$ kidney transplant, $M M F$ mycophenolate mofetil, qod every other day, $S B P$ systolic blood pressure may contribute to accelerated renal impairment. Similarly, a recent meta-analysis indicated that there is an association between severe AKI and high mortality in patients with COVID-19, suggesting a necessity for more precise care in patients with COVID-19 and AKI [11].

Drawing from a study conducted by Moris et al. [12], AKI is reported to develop in $58.5 \%$ of kidney recipients with COVID-19 during admission. In this study, we found all patients developed AKI (100\%) during hospitalization, which may prove that transplant recipients are at higher risk of AKI development compared with $29 \%$ AKI in critically ill patients in Wuhan, China [8]. Taken together, considering the fact that this is an observational study with its inherent biases, we cannot conclude whether AKI development contributes to COVID-19 progression. However, these results provide strong, but still inconclusive evidence that kidney transplant recipients with COVID-19 are more prone to develop AKI compared with other patients.

Strikingly, in this study, the progression of COVID-19 was not associated with the severity of pulmonary involvement on chest CT scan on admission. Several patients with moderate pulmonary involvement recovered without any complications; however, patient 4 deceased despite moderate involvement on chest $\mathrm{CT}$ scan. According to a study conducted by Tan et al. [13], patients with severe COVID-19 had an elevated CRP level at the early stage of the disease, even before CT scan findings. Also, we found that CRP level was elevated in all patients. These results indicate that despite the diagnostic value of CT scan at admission, it may not provide prognostic information in transplant recipients 
Table 2 Laboratory findings of six kidney transplant recipients with COVID-19 on admission

\begin{tabular}{|c|c|c|c|c|c|c|}
\hline & Patient 1 & Patient 2 & Patient 3 & Patient 4 & Patient 5 & Patient 6 \\
\hline $\mathrm{WBC}\left(\times 10^{9} / \mathrm{L}\right)(4-10.5)$ & 5.1 & 3.7 & 10.3 & 3.7 & 2 & 5.3 \\
\hline Lymphocyte $\left(\times 10^{9} / \mathrm{L}\right)(1-3.5)$ & 0.82 & 0.41 & 0.31 & 0.41 & 0.12 & 0.3 \\
\hline $\mathrm{Hb}(\mathrm{g} / \mathrm{dL})(13-17.5)$ & 12.1 & 10.6 & 11.2 & 9.6 & 5.1 & 8 \\
\hline Platelets $\left(\times 10^{9} / \mathrm{L}\right)(150-400)$ & 172 & 199 & 253 & 175 & 125 & 381 \\
\hline Baseline $\mathrm{Cr}(\mathrm{mg} / \mathrm{dL})(0.7-1.4)$ & 1.4 & 1.48 & 1.47 & 1.45 & 2.46 & 2.5 \\
\hline Admission $\mathrm{Cr}(\mathrm{mg} / \mathrm{dL})(0.7-1.4)$ & 2 & 2.2 & 3.5 & 2.4 & 3.8 & 3.5 \\
\hline Baseline eGFR $\left(\mathrm{mL} / \mathrm{min} / 1.73 \mathrm{~m}^{2}\right)(>90)$ & 59 & 52 & 41 & 40 & 22 & 15 \\
\hline Urea $(\mathrm{mg} / \mathrm{dL})(18-55)$ & 46 & 49 & 91 & 213 & 126 & 120 \\
\hline $\operatorname{ESR}(\mathrm{mm})(<18)$ & 28 & 56 & 86 & 96 & 46 & 110 \\
\hline $\mathrm{CRP}(\mathrm{mg} / \mathrm{L})(<6)$ & 14.8 & 99.2 & 154 & 83 & 147 & 150 \\
\hline Procalcitonin $(\mathrm{ng} / \mathrm{mL})(<0.36)$ & 0.55 & 0.2 & 0.33 & 0.45 & - & 0.72 \\
\hline Ferritin (ng/mL) (21.3-274.7) & $>2000$ & 1598 & 962.7 & 425 & $>2000$ & $>2000$ \\
\hline LDH (U/L) $(<480)$ & 1230 & 572 & 733 & 770 & 476 & 978 \\
\hline First-Troponin $(\mathrm{ng} / \mathrm{mL})(<26)$ & 193.6 & 6.1 & - & 33.7 & 233.7 & 49.4 \\
\hline D-dimer $(\mathrm{ng} / \mathrm{mL})(<250)$ & 1310.1 & - & 1162.7 & 971.7 & 472.4 & $>10,000$ \\
\hline $\operatorname{AST}(\mathrm{U} / \mathrm{L})(<38)$ & 67 & 83 & 37 & 36 & 45 & 61 \\
\hline ALT (U/L) $(<41)$ & 48 & 60 & 32 & 19 & 34 & 35 \\
\hline $\operatorname{ALP}(\mathrm{U} / \mathrm{L})(<270)$ & 158 & 110 & 173 & 120 & 90 & 200 \\
\hline Albumin (gr/dL) (3.5-5.2) & 3.2 & 3.5 & 2.7 & 3.4 & 4.4 & - \\
\hline Urine protein ${ }^{\mathrm{a}}$ & $3+$ & $1+$ & Trace & $2+$ & Negative & Trace \\
\hline
\end{tabular}

$A L P$ alkaline phosphatase, $A L T$ alanine transaminase, AST aspartate aminotransferase, COVID-19 coronavirus disease 2019, $C r$ creatinine, $C R P$ C-reactive protein, $e G F R$ estimated glomerular filtration rate, ESR erythrocyte sedimentation rate, $H b$ hemoglobin, $L D H$ lactate dehydrogenase, $W B C$ white blood cells

${ }^{a}$ Urine protein is described as: negative, $0 \mathrm{mg} / \mathrm{dL}$; trace, $15-30 \mathrm{mg} / \mathrm{dL} ; 1+, 30-100 \mathrm{mg} / \mathrm{dL} ; 2+, 100-$ $300 \mathrm{mg} / \mathrm{dL} ; 3+, 300-1000 \mathrm{mg} / \mathrm{dL} ; 4+$, more than $1000 \mathrm{mg} / \mathrm{dL}$ and other factors, including inflammatory biomarkers that may help us to detect the COVID-19 progression.

Since the outbreak of this disease in December 2019, it has been discussed that the novel coronavirus acts on lymphocytes, particularly $\mathrm{T}$ lymphocytes, resulting in $\mathrm{T}$ cell reduction. Besides, antimetabolite drugs work by suppressing the adhesion and proliferation of $\mathrm{T}$ lymphocytes $[14,15]$. Of note, the number of lymphocytes was clearly decreased in our patients, with the median of $0.36 \times 10^{9} / \mathrm{L}$ $\left(0.12-0.82 \times 10^{9} / \mathrm{L}\right)$, which is in line with that of Santeusanio et al. [16], who found absolute lymphocyte count $\leq 600$ cells/mL among all patients at admission. Given this experience, anti-proliferative agents (MMF, sirolimus, and azathioprine) were withdrawn at the time of admission in all patients. The role of antiviral therapies has been disputed since the outbreak of COVID-19; however, some studies suggest an effective role for hydroxychloroquine and lopinavir/ritonavir in reducing the viral load $[17,18]$. Zhang $\mathrm{H}$ et al. [19], studied five transplant recipients and reported that they administrated antiviral therapy (arbidol or oseltamivir) for all patients in line with immunosuppressants reduction in four patients. In addition, in a study conducted by Alberici $F$ et al. [6], the general management of COVID-19 was similar to the mentioned studies with the use of HCQ (95\%), methylprednisolone (100\%), and immunosuppression withdrawn
$(100 \%)$. Interestingly, although patients in this study were treated with anti-IL 6 drugs such as tocilizumab, the final outcome was not significantly different from other studies. In our patients, in accordance with previous studies, we started antiviral therapies in all patients. It is noteworthy to note that the treatment approach is in line with the standard protocols at the time of patients' admission.

The essential role of inflammation and cytokine storm in the progression of COVID-19 has been revealed so far [20]; therefore, urgently needed treatments based on suppressing the inflammation such as glucocorticoids are demanded to control COVID-19; so, we elevated the dose of prednisolone to $15 \mathrm{mg}$ daily. It is believed that cyclosporine may have effective roles in COVID-19 treatment by inhibiting the replication of the virus [21]; although, the same strategy did not work in the fourth case of our report who continued her cyclosporine. In addition, this patient developed sepsis during follow-up, which warrants more careful use of glucocorticoids in patients with COVID-19. Overall, it is important to note that the risk of rejection may increase with a reduction in immunosuppression; however, with regard to the high in-hospital mortality of COVID-19, clinicians should make different decisions based on patients' conditions.

Most notably, the mortality rate in our patients was $33.3 \%$, which is nearly consistent with the previous studies 
[6, 7]. According to a recent review study, Moris et al. [12], reported a cumulative mortality rate of $19.9 \%$ in kidney recipients with COVID-19. Pereira and colleagues [3] studied 90 solid-organ transplant (SOT) recipients including 46 patients with a history of kidney transplantation; they concluded that mortality (24\%) and severity (39\%) were significantly higher in transplant recipients compared with other patients. Moreover, according to a study conducted by Fernández-Ruiz et al. [22], SOT recipients developed more ARDS compared with others (38.9\% vs. 5.6\%). In a recent study in Wuhan, China, the mortality rate among patients with ARDS was 52.4\%, which has been described to be the leading cause of death on COVID-19 [23]. One of the essential characteristics of ARDS is the cytokine storm cascade, which has been proved to be the cause of sepsis, and can contribute to multi-organ failure [20]. In our study, the poor outcome in patient 4 may be related to the patient's ARDS, which was followed by sepsis. In addition, patient 6 deceased as a result of deterioration in respiratory status, which may indicate that respiratory involvement is the main cause of poor outcomes in patients with COVID-19; so, more supportive care must be considered in these patients.

\section{Limitations}

We would like to emphasize that our study has several limitations; however, we believe our study population is representative of patients diagnosed in our hospital. First, it is a single-center study on the Iranian population, and future multicenter studies on different ethnicities are demanded. Second, the small sample size of our study may affect the findings, and our results should be confirmed in larger studies.

\section{Conclusions}

In summary, in our case series of six kidney transplant recipients with COVID-19, two patients deceased (33.3\%) and all the patients developed AKI, which indicates that immunosuppression after kidney transplantation may be a risk indicator for poor outcomes in COVID-19.

Acknowledgements We are indebted to the Research Development Center of Sina Hospital for its support. The funding source had no role in the study design, data collection, and data analysis, data interpretation, writing of the manuscript, or decision of submission.

\section{Compliance with ethical standards}

Conflict of interest All the authors have declared no competing interest.
Ethical approval All procedures performed in studies involving human participants were in accordance with the ethical standards of the institutional and/or national research committee at which the studies were conducted (IR.TUMS.VCR.REC.1399.005) and with the 1964 Helsinki declaration and its later amendments or comparable ethical standards.

Informed consent Informed consent was obtained from all individual participants included in the study.

Data availability statement Data are available upon a reasonable request to the corresponding author.

\section{References}

1. COVID-19 Coronavirus Pandemic. Worldometer. https://www. worldometers.info/coronavirus/.

2. Aleebrahim-Dehkordi E, Reyhanian A, Saberianpour S, Hasanpour-Dehkordi A. Acute kidney injury in COVID-19; a review on current knowledge. J Nephropathol 2020;9(4):e31-e.

3. Pereira MR, Mohan S, Cohen DJ, Husain SA, Dube GK, Ratner LE et al. COVID-19 in solid organ transplant recipients: Initial report from the US epicenter. Am J Transplant. 2020;20(7):18008. https://doi.org/10.1111/ajt.15941.

4. Clinical management of COVID-19. World Health Organization. https://www.who.int/publications/i/item/clinical-manag ement-of-covid-19.

5. COVID-19 Epidemiology. COVID-19 Epidemiology Committee. http://corona.behdasht.gov.ir/.

6. Alberici F, Delbarba E, Manenti C, Econimo L, Valerio F, Pola A et al. A single center observational study of the clinical characteristics and short-term outcome of 20 kidney transplant patients admitted for SARS-CoV2 pneumonia. Kidney Int. 2020;97(6):1083-8. https://doi.org/10.1016/j.kint.2020.04.002.

7. Abolghasemi S, Mardani M, Sali S, Honarvar N, Baziboroun M. COVID-19 and kidney transplant recipients. Transplant Infect Dis 2020:e13413. https://doi.org/10.1111/tid.13413.

8. Yang X, Yu Y, Xu J, Shu H, Liu H, Wu Y et al. Clinical course and outcomes of critically ill patients with SARS-CoV-2 pneumonia in Wuhan, China: a single-centered, retrospective, observational study. Lancet Respir Mede. 2020.

9. Acute Kidney Injury guideline. KDIGO Guidelines. https://kdigo. org/guidelines/acute-kidney-injury/.

10. Wang Y, Lv Y, Liu Q. SARS-CoV-2 infection associated acute kidney injury in patients with pre-existing chronic renal disease: A report of two cases. Immunity, inflammation and disease. 2020. https://doi.org/10.1002/iid3.333.

11. Ali H, Daoud A, Mohamed MM, Salim SA, Yessayan L, Baharani $\mathbf{J}$ et al. Survival rate in acute kidney injury superimposed COVID-19 patients: a systematic review and meta-analysis. Ren Fail. 2020;42(1):393-7. https://doi.org/10.1080/0886022x.2020. 1756323.

12. Moris D, Kesseli SJ, Barbas AS. Kidney transplant recipients infected by COVID-19: Review of the initial published experience. Transplant Infect Dis. 2020. https://doi.org/10.1111/tid. 13426.

13. Tan C, Huang Y, Shi F, Tan K, Ma Q, Chen Y et al. C-reactive protein correlates with computed tomographic findings and predicts severe COVID-19 early. J Med Virol. 2020;92(7):856-62. https://doi.org/10.1002/jmv.25871.

14. Qin C, Zhou L, Hu Z, Zhang S, Yang S, Tao Y et al. Dysregulation of immune response in patients with coronavirus 2019 (COVID19) in Wuhan, China. Clin Infect Dis. 2020;71(15):762-8. https:// doi.org/10.1093/cid/ciaa248. 
15. McMurray RW, Harisdangkul V. Mycophenolate mofetil: selective T cell inhibition. Am J Med Sci. 2002;323(4):194-6. https://doi. org/10.1097/00000441-200204000-00005.

16. Santeusanio AD, Zendel A, Fenig Y, Mahamid A, Bhansali A, De Boccardo $\mathrm{G}$ et al. Kidney transplantation using lymphocyte depleting induction and standard maintenance immunosuppression at the height of the SARS-CoV-2 pandemic in New York City: A single-center experience. Clin Transplant. 2020;34(9):e14055.

17. Gautret P, Lagier JC, Parola P, Hoang VT, Meddeb L, Mailhe $\mathrm{M}$ et al. Hydroxychloroquine and azithromycin as a treatment of COVID-19: results of an open-label non-randomized clinical trial. Int J Antimicrob Agents. 2020;56(1):105949. https://doi.org/10. 1016/j.ijantimicag.2020.105949.

18. Dirim AB, Demir E, Ucar AR, Garayeva N, Safak S, Oto OA et al. Fatal SARS-CoV-2 infection in a renal transplant recipient. CEN Case Rep. 2020;9(4):409-12. https://doi.org/10.1007/ s13730-020-00496-4.

19. Zhang H, Chen Y, Yuan Q, Xia QX, Zeng XP, Peng JT et al. Identification of kidney transplant recipients with coronavirus disease 2019. Eur Urol. 2020;77(6):742-7. https://doi.org/10.1016/j. eururo.2020.03.030.

20. Ragab D, Salah Eldin H, Taeimah M, Khattab R, Salem R. The COVID-19 Cytokine storm; what we know so far. Front Immunol. 2020;11:1446. https://doi.org/10.3389/fimmu.2020.01446.
21. Zumla A, Hui DS, Azhar EI, Memish ZA, Maeurer M. Reducing mortality from 2019-nCoV: host-directed therapies should be an option. Lancet (London, England). 2020;395(10224):e35-6. https://doi.org/10.1016/s0140-6736(20)30305-6.

22. Fernández-Ruiz M, Andrés A, Loinaz C, Delgado JF, LópezMedrano F, San Juan R et al. COVID-19 in solid organ transplant recipients: A single-center case series from Spain. Am J Transplant. 2020;20(7):1849-58. https://doi.org/10.1111/ajt.15929.

23. Wu C, Chen X, Cai Y, Xia J, Zhou X, Xu S et al. Risk factors associated with acute respiratory distress syndrome and death in patients with coronavirus disease 2019 pneumonia in Wuhan China. JAMA Internal Med. 2020;180(7):934-43. https://doi.org/ 10.1001/jamainternmed.2020.0994.

Publisher's Note Springer Nature remains neutral with regard to jurisdictional claims in published maps and institutional affiliations. 